\title{
RANCANG BANGUN TELEMETRI ARUS BEBAN PERALATAN ELEKTRONIK PADA RUANG PENUMPANG KAPAL FERRY BERBASIS LONG RANGE WIRELESS COMMUNICATIONS (LoRA)
}

\author{
Aldian Dwi Pamungkas', Lilik Subiyanto ${ }^{1}$, Afif Zuhri Arfianto ${ }^{1}$, Hendro Agus Widodo ${ }^{1}$ \\ ${ }^{1}$ Jurusan Teknik Kelistrikan Kapal \\ Politeknik Perkapalan Negeri Surabaya \\ email : aldiandwipa6@gmail.com
}

diterima tanggal : 15 Maret 2019, disetujui tanggal : 23 Mei 2019

\begin{abstract}
Abstrak
Perkembangan teknologi informasi baik software dan hardware menunjang perkembangan dalam berbagai bidang khususnya dalam bidang elektronika. Kemajuan ini bisa dimanfaatkan dalam pembuatan sistem otomatisasi dan pengontrolan terhadap komponen-komponen elektronika dan listrik. Dengan meningkatnya kebutuhan pamantauan sistem secara real time, maka berkembang pula sebuah model yang lebih dari sekedar protabel yang dapat dibawa kemana - mana, yaitu dengan menggunakan sistem telemetri (pengukuran jarak jauh). Penelitian ini membuat prototipe yang digunakan untuk teknologi monitoring jarak jauh telemetri peralatan elektronik pada ruang penumpang kapal ferry dengan menggunakan wireless communications.

Penggunaan radio frekuensi ini digunakan untuk peralatan elektronik yang lokasinya berada pada ruang penumpang..Sistem tersebut dibuat menggunakan sensor arus ACS 712 dan sensor tegangan ZMPT 101B untuk mengukur arus dan tegangan yang dimonitoring berbasis long range wireless communications (LoRa) untuk mejaga kekuatan sinyal penguat dan jarak yang dapat dicapai oleh LoRa tersebut. Dengan memanfaatkan frekuensi dari LoRa diharapkan dapat memonitoring arus beban dan tegangan yang dihasilkan oleh peralatan elektronik pada ruang penumpang kapal ferry tersebut.

Dari alat monitoring tersebut didapatkan Hasil Pengujian pada beban TV 21 inch dengan daya 27 Watt dan tegangan 19 Volt didapatkan presentase error arus 4,91\%, Presentase Error Tegangan 0,8\%, Presentase error Daya 4,2 \%, Hasil Pengujian pada beban Kulkas Showcase dengan daya $170 \mathrm{~W}$ dan tegangan 220 Volt didapatkan presentase error arus 1,9\%, Presentase Error Tegangan 0,7\%, Presentase error Daya 1,38\%, Hasil Pengujian pada beban AC daya $0.5 \mathrm{KW}$ dan tegangan 220 Volt didapatkan presentase error arus $3 \%$, Presentase Error Tegangan 2,16\%, Presentase error Daya $5 \%$ Dan dapat disimpulkan alat monitoring tersebut berjalan dengan baik.
\end{abstract}

Kata Kunci: Long Range Wireless Communications, Telemetri

\begin{abstract}
The development of information technology both software and hardware supports development in various fields, especially in the field of electronics. This progress can be used in making automation systems and controlling electronic and electrical components. With the increasing need for system monitoring in real time, a model that is more than just a portable storage can be developed, using telemetry (remote measurement) systems. This research makes a prototype that is used for remote monitoring of electronic equipment telemetry in the passenger space of ferries using wireless communications.

The use of this radio frequency is used for electronic equipment located in the passenger space. The system is made using ACS 712 current sensor and ZMPT 101B voltage sensor to measure current and voltage monitored by long range wireless communications (LoRa) to maintain the strength of the amplifier signal and the distance that the LoRa can reach. By utilizing the frequency of the LoRa, it is expected to monitor the load current and voltage generated by electronic equipment in the ferry passenger's passenger space.

From the monitoring tool obtained the test results of testing root Television with power $27 \mathrm{~W}$ and Voltage 19 Volt obtained the percentage of current error $4.91 \%$, percentage error voltage $0.8 \%$, percentage error power $4.2 \%$, the results of testing root Refrigeator Showcase with power $170 \mathrm{~W}$ and voltage 220 Volt obtained percentage error current 1, 9\%, Error Percentage Voltage 0.7\%, Percentage error Power 1.38\%, Results of testing root AC with power $0.5 \mathrm{KW}$ and voltage 220 Volt obtained percentage error current $3 \%$, Percentage Error Voltage $2.16 \%$, Percentage error Power 5\% and can be concluded tool the monitoring goes well.
\end{abstract}

Keyword : Long Range Wireless Communications, Telemetry 


\section{PENDAHULUAN}

Dalam dunia perkapalan Sebagian besar teknologi monitoring masih menggunakan teknologi konvensional diantaranya monitoring arus, monitoring daya maupun monitoring lampu emergency kapal, padahal saat ini Perkembangan teknologi informasi baik software dan hardware menunjang perkembangan dalam berbagai bidang khususnya dalam bidang elektronika.

Kemajuan ini bisa dimanfaatkan dalam pembuatan sistem otomatisasi dan pengontrolan terhadap komponen-komponen elektronika dan listrik terutama sekali monitoring arus beban dan tegangan pada ruang penumpang untuk dapat melakukan pengontrolan daya yang keluar. Proses pengukuran merupakan proses yang sangat penting dilakukan dalam tahap pengembangan sebuah peralatan elektronik. Hasil dari proses pengukuran dapat digunakan untuk menggetahui karakteristik dari peralatan elektronik yang sedang di kembangkan [1].

Alat - alat ukur yang tersedia di pasaran merupalan alat ukur standart yang sering kali digunakan pada keadaan - keadaan yang bersifat umum, seperti thermometer yang digunakan untuk mengukur suhu benda atau ruangan yang bentuknya portable, avometer yang digunakan untuk mengukur besarnya tegangan, arus serta tahanan listrik yang bentuknya juga portable dan menjadi mater standart untuk mengukur besaran - besaran listik. Dalam hal ini alat ukur yang tersedia hanya dapat digunakan dalam keadaan yang relatif umum, meskipun dipasaran alat ukur - alat ukur tersebut sudah berkembang dengan memanfaatkan teknologi digital. Dengan meningkatnya kebutuhan pamantauan sistem secara real time, maka berkembang pula sebuah model yang lebih dari sekedar protabel yang dapat dibawa kemana - mana, yaitu dengan menggunakan sistem telemetri (pengukuran jarak jauh) [2].

Model monitoring ini dilakukan dengan memanfaatkan gelombang radio sebagai media pengirim data, kelebihan dibandingkan dengan sistem portable adalah bahwa sistem ini dapat digunakan secara real time dan tidak perlu melakukan proses pengukuran didekat objek yang akan diukur. Kemajuan dalam bidang teknologi dan ilmu pengetahuan khususnya dalam bidang teknik kendali (teknik monitoring) telah berkembang dengan pesat [3].

Perkembangan ini mempermudah komunikasi dan pengendalian alat elektronik khususnya peralatan elektronik pada ruang penumpang kapal ferry. Seiring perkembangannya saat ini telah berkembang sistem kendali monitoring arus beban jarak jauh menggunakan Long Range Wireless Communications (LoRa) sehingga tidak perlu menggunakan cara konvensional [4] [5]. Kendali monitoring arus beban jarak jauh ini sangat dibutuhkan pada peralatan elektronik ruang penumpang kapal ferry. Hal ini dimaksudkan untuk monitoring arus beban dan tegangan pada ruang penumpang

\section{METODE PENELITIAN}

Pada metode penelitian ini akan dijelaskan gambaran umum metode penelitian yang akan dilakukan dalam menyelesaikan penelitian. Metode tersebut berisi tahap-tahap pengerjaan yang dapat dilihat pada Gambar 1. dibawah ini:

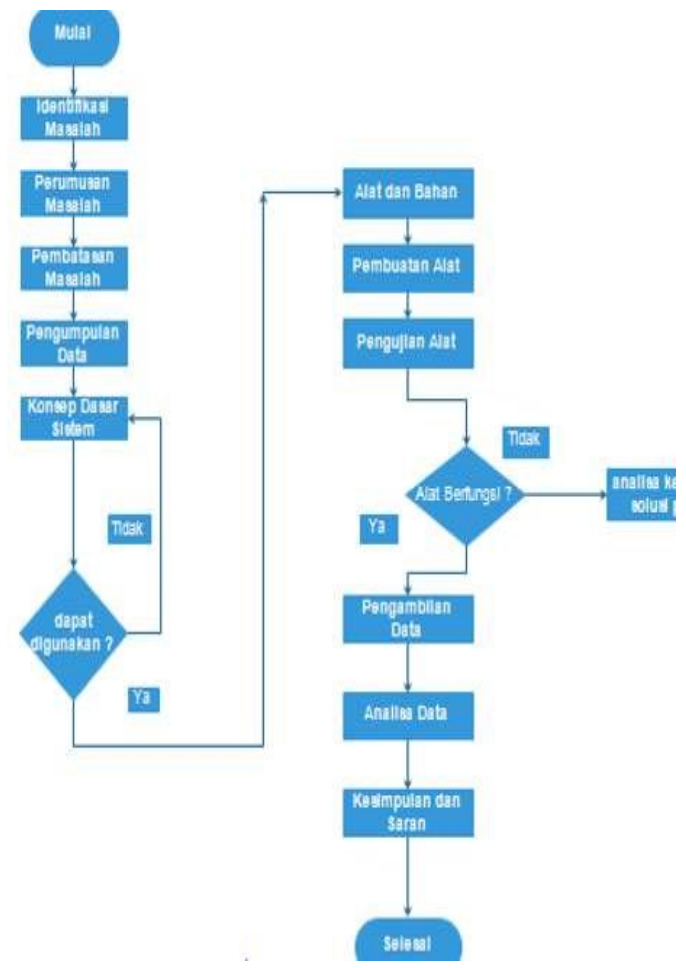

Gambar 1 Alur penelitian

\subsection{Membuat Konsep Desain Sistem}

Dalam melakukan perancangan sistem kerja dari Monitoring Arus Beban dan tegangan telemetri berbasis LoRa yang akan dibuat. Sistem kerja yang akan diterapkan dapat dilihat pada Gambar 2. dibawah ini :

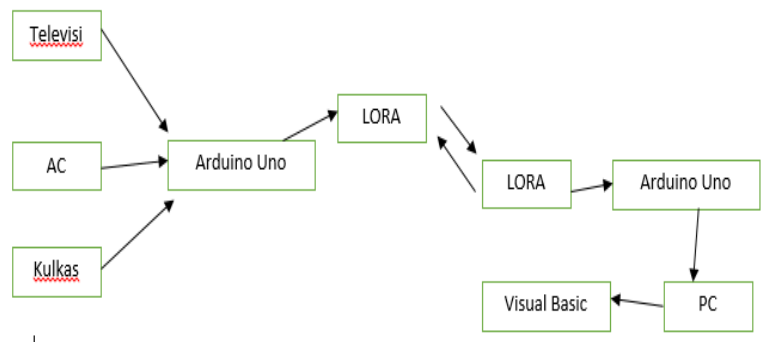

Gambar 2 : Block Diagram Sistem Arus Beban dan tegangan Telemetri berbasis LoRa 
Pada Block diagram sistem arus beban dan tegangan telemetri berbasis LORA dapat dilihat Pemancar data yang digunakan adalah perangkat elektronik yang ada pada ruang penumpang kapal ferry . Perangkat elektronik tersebut adalah Televisi, Kulkas dan AC. Kemudian dilakukan pengukuran dengan menggunakan Sensor Arus dan sensor tegangan untuk mengetahui hasil pengukuran arus dan tegangan. Kemudian data yang dihasilkan dari pengukuran sensor arus dan sensor tegangan disesuaikan serta diolah oleh Arduino yang sudah diprogramkan dan data yang diterima akan dimodulasi dengan menggunakan gelombang radio yang akan ditransmisikan oleh LoRa.

Kemudian data yang ditransmisikan tersebut diterima oleh penerima LoRa[6] [7] [8]. Kemudian Data disesuaikan serta diolah oleh Arduino yang sudah di program untuk di tampilkan oleh LCD pada display untuk mengetahui hasil pengukuran tersebut serta diteruskan ke visual basic.

\subsection{Pembuatan Alat}

Pada pembuatan hardware berdasarkan spesifikasi sistem Arus beban Telemetri Pada Ruang Penumpang Kapal Ferry berbasis Long Range Wireless Communications dilakukan uji sensor arus dan tegangan pada alat monitoring telemetri arus beban. Pengujian beban dilakukan pada ruang penumpang kapal ferry. Adapun alat yang akan dibuat seperti desain pada Gambar 3 dibawah ini :

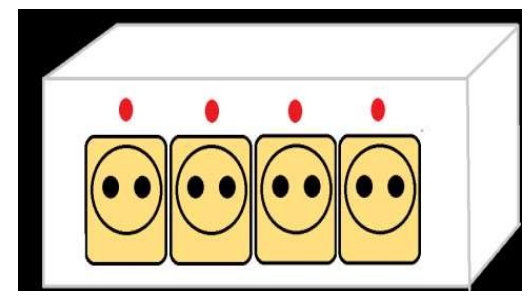

Gambar 3 : Desain Alat Monitoring Telemetri Beban

Pada Gambar 3. diatas adalah desain alat monitoring telemetri beban yang direncanakan tampak gambar pada bagian depan alat yang direncanakan dengan ukuran panjang $31 \mathrm{~cm}$ lebar $19 \mathrm{~cm}$ dan tinggi $10 \mathrm{~cm}$.

\subsection{Pengujian Alat}

Pengujian alat dilakukan untuk mengetahui kemampuan kerja dari alat yang dibuat apakah sudah sesuai dengan rancangan. Kemudian dilakukan pengujian arus dan tegangan pada ruang penumpang kapal ferry. Pengujian beban pada ruang penumpang tersebut meliputi AC, Televisi dan Kulkas yang berada pada ruang penumpang kapal ferry. Pengujian dilakukan dengan membandingkan pengujian manual pada arus dan tegangan menggunakan alat ukur avometer untuk mengetahui kinerja alat monitoring telemetri beban.

\subsection{Sistem Kerja Alat dan Wiring Diagram}

Apabila ditemukan kegagalan dalam proses pengujian maka akan dilakukan analisis kegagalan dan permasalahan yang muncul. Kemudian dicari solusi untuk memperbaiki masalah tersebut sehingga alat dan berfungsi dengan maksimal. Berikut adalah wiring diagram alat monitoring telemetri arus beban pada Gambar 4 dibawah ini :

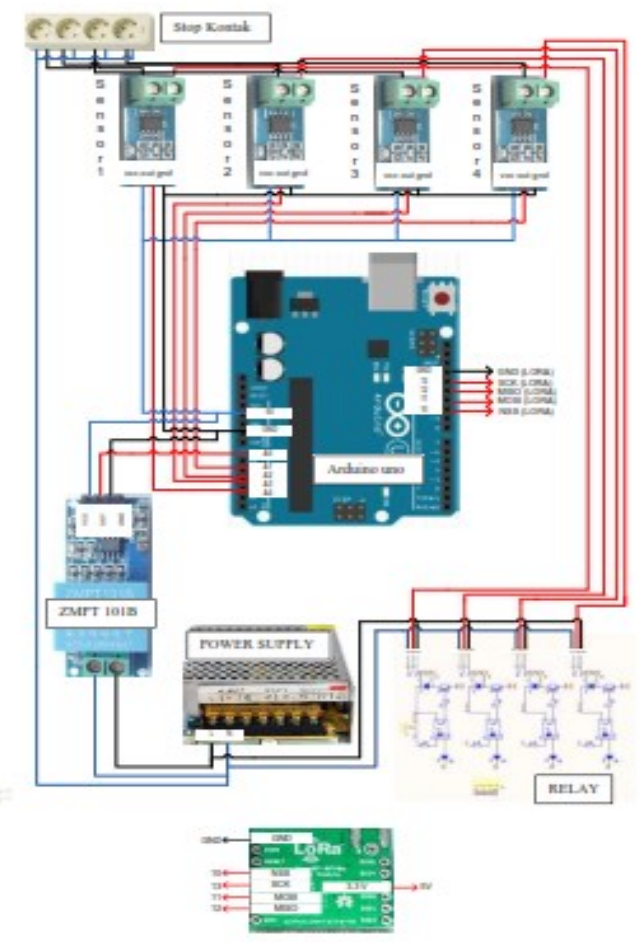

Gambar 4 Wiring Diagram

Dari Gambar 4 wiring alat monitoring telemetri arus beban terdapat empat sensor arus dan sensor tegangan untuk membaca keluaran berupa arus dan tegangan yang diukur. Sensor tegangan masuk pada port Arduino A0, Sensor arus 1 masuk pada port Arduino A04, Sensor arus 2 masuk pada port Arduino A3, Sensor Arus 3 masuk pada port Arduino A2, Sensor arus 4 masuk pada port Arduino A1, Modul LORA masuk pada port Rx dan port Tx pada web client kemudian pada web server sebagai penerima data modul lora masuk pada port Arduino Rx dan Tx yang kemudian diteruskan ke monitor untuk ditampilkan hasil pembacaan data tersebut oleh visual basic dimana pin Arduino dari A1 hingga A5 terhubung dengan satu $\mathrm{ADC}$ dalam resolusi 10 bit.

\section{PEMBAHASAN}

Pada tahap ini adalah tahapan dimana pembahasan mengenai perancangan alat monitoring arus beban telemetri dan pembuatan alat hingga pengujian beban 
yang akan dilakukan pada ruang penumpang dan ruang penumpang very important person KMP Joko Tole sehingga pada nantinya dapat dianalisa mengenai kerja alat dan kesesuaian alat monitoring telemetri arus beban peralatan elektronik dengan perancangan alat yang telah dikerjakan dengan hasil pengujian lapangan yang dilakukan pada kapal ferry KMP Joko Tole sehingga permasalahan yang ada di kapal mengenai arus beban dan tegangan yang fluktuatif dapat dilakukan monitoring untuk menentukan solusi dalam mengatasi permasalahan tersebut.

\subsection{Hasil dan Pengujian Sensor Tegangan}

Pada tahap ini adalah penjelasan dari perancangan alat monitoring telemetri arus beban terhadap sensor tegangan yang digunakan adalah sensor tegangan AC zmpt101b dimana pada sensor tegangan AC zmpt101b adalah modul yang digunakan untuk mengukur Tegangan AC 1 Fasa. Sensor tegangan zmpt101b dirancang dengan menggunakan transformator sehingga hanya dapat digunakan untuk membaca tegangan AC kemudian tegangan akan dikonversi diskritnya ke dalam analog to digital converter pada pin A0 dengan resolusi 10 bit [4]. sensor zmpt101b memiliki spesifikasi yang baik dalam membaca data yang diterima

Dari Gambar 2.4 wiring rangkaian tegangan alat monitoring telemetri dapat diketahui bahwa sensor tegangan masuk pada port Arduino A4 dan kemudian diproses menjadi ADC4. Dengan bilangan biner 10 bit dan mampu membaca tegangan maksimal $247.5 \mathrm{~V}$ sesuai dengan program yang telah dikerjakan .dan setiap pin memiliki konverter yaitu analog to digital dimana konverter dapat merubah sinyal yang diterima pin analog yaitu berupa tegangan kemudian diubah menjadi angka agar mudah dalam pembacaanya.Untuk lebih jelas dapat dilihat pada program Tegangan alat monitoring telemetri seperti dibawah ini :

Tabel 4. 2 Pengujian Sensor Tegangan

\begin{tabular}{|c|c|c|c|}
\hline V Ukur & V Uji & $\begin{array}{c}\text { Konverensi } \\
\text { V Uji }\end{array}$ & Error \\
\hline $30 \mathrm{~V}$ & $31.15 \mathrm{~V}$ & 128.6 & $3.83 \%$ \\
\hline $40 \mathrm{~V}$ & $39.57 \mathrm{~V}$ & 163 & $1.07 \%$ \\
\hline $50 \mathrm{~V}$ & $48.48 \mathrm{~V}$ & 200.2 & $3.04 \%$ \\
\hline $60 \mathrm{~V}$ & $58.39 \mathrm{~V}$ & 241.1 & $2.68 \%$ \\
\hline $70 \mathrm{~V}$ & $68.04 \mathrm{~V}$ & 281 & $2.8 \%$ \\
\hline $80 \mathrm{~V}$ & $78.69 \mathrm{~V}$ & 324.9 & $1.63 \%$ \\
\hline $90 \mathrm{~V}$ & $89.09 \mathrm{~V}$ & 367.9 & $1.01 \%$ \\
\hline $100 \mathrm{~V}$ & $98.75 \mathrm{~V}$ & 407.8 & $1.25 \%$ \\
\hline $110 \mathrm{~V}$ & $109.15 \mathrm{~V}$ & 450.7 & $0.77 \%$ \\
\hline $120 \mathrm{~V}$ & $120.04 \mathrm{~V}$ & 495.7 & $0.03 \%$ \\
\hline $130 \mathrm{~V}$ & $129.7 \mathrm{~V}$ & 535.6 & $0.23 \%$ \\
\hline $140 \mathrm{~V}$ & $140.84 \mathrm{~V}$ & 581.6 & $0.6 \%$ \\
\hline $150 \mathrm{~V}$ & $150.99 \mathrm{~V}$ & 623.5 & $0.66 \%$ \\
\hline
\end{tabular}

\begin{tabular}{|c|c|c|c|}
\hline $160 \mathrm{~V}$ & $160.89 \mathrm{~V}$ & 664.4 & $0.55 \%$ \\
\hline $170 \mathrm{~V}$ & $170.8 \mathrm{~V}$ & 705.4 & $0.47 \%$ \\
\hline $180 \mathrm{~V}$ & $180.45 \mathrm{~V}$ & 745.2 & $0.25 \%$ \\
\hline $190 \mathrm{~V}$ & $190.85 \mathrm{~V}$ & 788.2 & $0.44 \%$ \\
\hline $200 \mathrm{~V}$ & $200.01 \mathrm{~V}$ & 826 & $0.005 \%$ \\
\hline $210 \mathrm{~V}$ & $210.41 \mathrm{~V}$ & 868.9 & $0.19 \%$ \\
\hline $220 \mathrm{~V}$ & $220.57 \mathrm{~V}$ & 910.95 & $0.25 \%$ \\
\hline
\end{tabular}

\subsection{Hasil dan Pengujian Sensor Arus}

Ada tahap ini adalah penjelasan dari perancangan alat monitoring telemetri arus beban terhadap sensor arus yang digunakan adalah sensor arus ACS 712. Sensor arus ini berfungsi mengukur arus yang mengalir pada beban dimana pada sensor arus ACS 712 adalah modul yang digunakan untuk mengukur arus AC 1 Fasa. Sensor tegangan ACS 712 menggunakan fungsi transfer adalah korelasi antara nilai besaran fisis yang terukur oleh sensor terhadap nilai ADC (Analog to Digital Converter) kemudian tegangan akan dikonversi diskritnya ke dalam analog to digital converter pada pin A1A4 menggunakan rangkaian seri yang memakai empat sensor arus ACS 712

Dengan resolusi 10 bit. sensor arus ACS 712 memiliki spesifikasi yang baik dalam membaca data yang diterima namun hasil pembacan pada arus bolak balik cenderung fluktuatif. Pada Wiring arus alat monitoring telemetri arus beban dapat dilihat pengalamatan pin Arduino Sensor arus 1 masuk pada port Arduino A4, Sensor arus 2 masuk pada port Arduino A3, Sensor Arus 3 masuk pada port Arduino A2, Sensor arus 4 masuk pada port Arduino A1.Seperti halnya Sensor tegangan AC, Sensor Arus ACS 712 jug disambungkan dengan pin analog Arduino Uno.

Sehingga prosesnya juga dikonversi analog to digital (ADC) dengan jangkaun 0 volt di representasikan sebagai data 0 dan volt direpresentasikan sebagai data 1023 Sensor arus ACS712 memiliki sensitifita tegangan sebesar 66-185 $\mathrm{mV} / \mathrm{A}$. Dari spesifikasi datasheet sensor arus ACS712 dapa mengukur dari arus (-) sampai arus (+) Sensor arus dengan sensitifitas $185 \mathrm{mV} / \mathrm{A}$ dapa membaca pengukuran dari -5 sampai +5 , Sensor arus ACS712 $20 \mathrm{~A}$ dengan sensitifitas $100 \mathrm{mV} / \mathrm{A}$ dengan pengukuran dari -20 sampai +20 . Sehingga untuk menghasilkan data $0 \mathrm{~A}(\mathrm{Nol})$ maka tegangan yang terbaca dikurangi 2.5 Volt atau setengah kali tegangan suplai (vcc) agar mendapat nilai 0A karena sensor arus ACS712 menggunakan tegangan terbaca maka harus dibagi dengan nilai sensitifitas sesuai spesifikasi sensor yang digunakan. Sehingga dirumuskan [4] maka : 


$$
\text { Hasil Pengukuran Arus }=\frac{\text { nilai ADC } x\left[\frac{5 \text { volt }}{1023}\right] \cdot 2 \times 5}{\text { sensitif sensor }}
$$

Dari Program sensor arus 1 diatas sensor arus 1 masuk pada pengalamatan arduino pin A4 dan dapat dilihat bahwa nilai 4.95 adalah nilai baca maksimal pada sensor tegangan dibagi dengan jumlah maksimal bit arus 1024 akan menghasilkan arus temp. Kemudian arus baca adalah hasil dari arus temp dibagi dua kemudian dikalikan dengan konstanta 0.7071 yang dibaca dan diteruskan pada tampilan led sehingga menghasilkan arus yang terbaca pada sensor arus 1 alat monitoring arus beban.

Kemudian dilakukan pengujian sensor arus ACS 712 sensor arus pertama. Data yang diambil adalah arus dengan step 0.5 volt. Data ini untuk menguji seberapa presisinya sensor arus . Data hasil pengujian sensor arus kemudian ditabelkan untuk mengetahui berapa error yang dihasilkan oleh alat ini. Untuk mengetahui errornya pada Tabel 4.3dibawah ini,

\begin{tabular}{|c|c|c|c|}
\hline Arus Ukur & Arus Uji & $\begin{array}{c}\text { Konverensi } \\
\text { Arus Uji }\end{array}$ & Error(\%) \\
\hline $2.0 \mathrm{~A}$ & $2.04 \mathrm{~A}$ & 417.7 & $2 \%$ \\
\hline $2.5 \mathrm{~A}$ & $2.51 \mathrm{~A}$ & 514 & $0.4 \%$ \\
\hline $3.0 \mathrm{~A}$ & $3.02 \mathrm{~A}$ & 618.4 & $0.66 \%$ \\
\hline $3.5 \mathrm{~A}$ & $3.55 \mathrm{~A}$ & 727 & $1.42 \%$ \\
\hline $4.0 \mathrm{~A}$ & $3.94 \mathrm{~A}$ & 806.9 & $1.5 \%$ \\
\hline $4.5 \mathrm{~A}$ & $4.45 \mathrm{~A}$ & 911.36 & $1.11 \%$ \\
\hline $5.0 \mathrm{~A}$ & $4.98 \mathrm{~A}$ & 1019.9 & $0.4 \%$ \\
\hline
\end{tabular}

\begin{tabular}{|c|c|c|c|}
\hline Arus Ukur & Arus Uji & $\begin{array}{c}\text { Konverensi } \\
\text { Arus Uji }\end{array}$ & Error(\%) \\
\hline $0.5 \mathrm{~A}$ & $0.5 \mathrm{~A}$ & 102.4 & $0 \%$ \\
\hline $1 \mathrm{~A}$ & $1 \mathrm{~A}$ & 204.8 & $0 \%$ \\
\hline $1.5 \mathrm{~A}$ & $1.56 \mathrm{~A}$ & 319.4 & $4 \%$ \\
\hline
\end{tabular}

\section{KESIMPULAN}

1. Berdasarkan Hasil Pengujian beban 1 pada tabel 4.3 didapatkan presentase error arus $4,91 \%$,Presentase Error Tegangan 0,8\%, Presentase error Daya 4,2 \% LORA adalah modulasi yang sangat efektif dan stabil dalam mengirimkan data namun terkadang memerlukan waktu yang lama untuk proses connection.

2. Berdasarkan hasil data pengujian tersebut dapat disimpulkan arus, tegangan dan daya yang terdapat pada ruang penumpang kapal KMP JokoTole fluktuatif. Hal ini perlu dilakukan monitoring arus beban yang ada di kapal terutama pada sistem safety alarm, perangkat elektronik , pompa-pompa demi keselamatan pelayaran yang mana pada KMP Joko Tole masih menggunakan teknologi konvensional dan tidak adanya dukungan data sistem kelistrikan yang memadai.

\section{DAFTAR PUSTAKA}

[1] Arfianto, A. Z., \& Affandi, A. (2010). Rancang Bangun Layanan Website Interaktif Pada Sistem Komunikasi Vessel Messaging System (VMeS). Bachelor Thesis, Surabaya Institute of Technology, Surabaya, Indonesia.

[2] Rhapsody, M. R., Arfianto, A. Z., \& Utari, D. A. (2017, December). Penggunaan IoT untuk Telemetri Efisiensi Daya pada Hybrid Power System. In Seminar MASTER PPNS (Vol. 2, No. 1, pp. 67-72).

[3] Djuniadi, D., Anis, S., \& Pribadi, F. S. (2011). Sistem Akuisisi Data Berbasis Telemetri. Sainteknol: Jurnal Sains dan Teknologi, 9(1)

[4] Subiyanto, L., Rahmat, M. B., Budiawati, R., Handoko, C. R., \& Arfianto, A. Z. (2019). Sistem Navigasi dan Komunikasi. Pustaka Teknik Kelistrikan Kapal, 1(1), 1-70.

[5] Hasin, M. K., Rinanto, N., Arfianto, A. Z., Utari, D. A., \& Sa'diyah, A. (2018). Ekstrasi Data Citra Koordinat Bumi Pada Peta Digital Pesebaran Ikan. Jurnal Teknologi Informasi dan Ilmu Komputer, 5(6), 717-722.

[6] Putra, T. A., Arfianto, A. Z., Rahmat, M. B., Hasin, M. K., Utari, D. A., Nasir, M., \& Hidayat, D. (2018). Komunikasi Data Bluetooth untuk Perangkat Informasi Persebaran Ikan (Portable Virtual Assistant) pada Kapal Nelayan Tradisional. Jurnal Teknologi Maritim, 1(2), 4552.

[7] Irwan, Sutopo B., 2005, Sistem Pengendalian Suhu Menggunakan AT89S51 dengan Tampilan di PC, Skripsi UGM, Yogyakarta

[8] S.Agus (2003). Teknik Dasar Kelistrikan Kapal .Jakarta .Kemendikbud 
Halaman ini sengaja dikosongkan 